\title{
Europe in sad decline
}

\section{London}

EUROPEAN semiconductor researchers say that last month's decision by the Dutch electronics company Philips to disband a research group studying gallium arsenide heterostructures, is part of a continuing wave of cutbacks in support for long-term companies. Coming as it does after recent cuts in semiconductor research by the British companies GEC and Plessey, this decision means that semiconductor sider forging closer links with Japanese companies which can still afford to expand

Almost half of the 390 staff at Philips Research Laboratories in Redhill, Surrey, will be shed during the next two years, including the 15-strong group working on gallium arsenide semiconductors. Bruce Joyce, director of the Science and Engineering Research Council (SERC)'s semiconductor materials Interdisciplinary $\mathrm{Re}$ search Centre at Imperial College, London, says that the loss of the gallium arsenide group is a "serious blow". The Philips researchers collaborate extensively with research groups in British universities.

Both Joyce and Professor Colin Humphreys, from the University of Cambridge, who is chairman of SERC's Materials Commission, say that major European companies seem to regard gallium arsenide as a perpetual 'tomorrow's material', which may never justify a large research and development effort. At the same time, Japanese companies are invesresearch on semiconductors by European groups at UK universities must now contheir research efforts.

ting heavily, to exploit the potential of gallium arsenide to give faster electronic devices and to develop its electrical response to light as the basis for an optical electronics industry.

SERC currently spends about $£ 3$ million a year on the semiconductor centre at Imperial College and its low-dimensional structures and devices initiative, in addition to strong research grant support for semiconductor research. This falls within SERC's category of strategic research, where future commercial applications are expected. Traditionally, this spending has been justified as underpinning British industry. But Humphreys says this has become "a very dangerous argument" for semiconductor research, with the British and now the European industrial research effort declining.

SERC's expenditure on semiconductor research may in future aim at providing a strong British research base to attract overseas investment, rather than at supporting British industry. There are signs that this is already happening. The Interdisciplinary Research Centre at Imperial College agreed a five-year collaborative research project on semiconductor films with the Research Development Corporation of Japan earlier this year, which will bring in several million pounds of Japanese money (see Nature 343, 300; 1990); and the Japanese electronics company Sharp is to open a new research laboratory in Oxford in 1992, eventually employing 100 scientists including an optical electronics research team.

Peter Aldhous

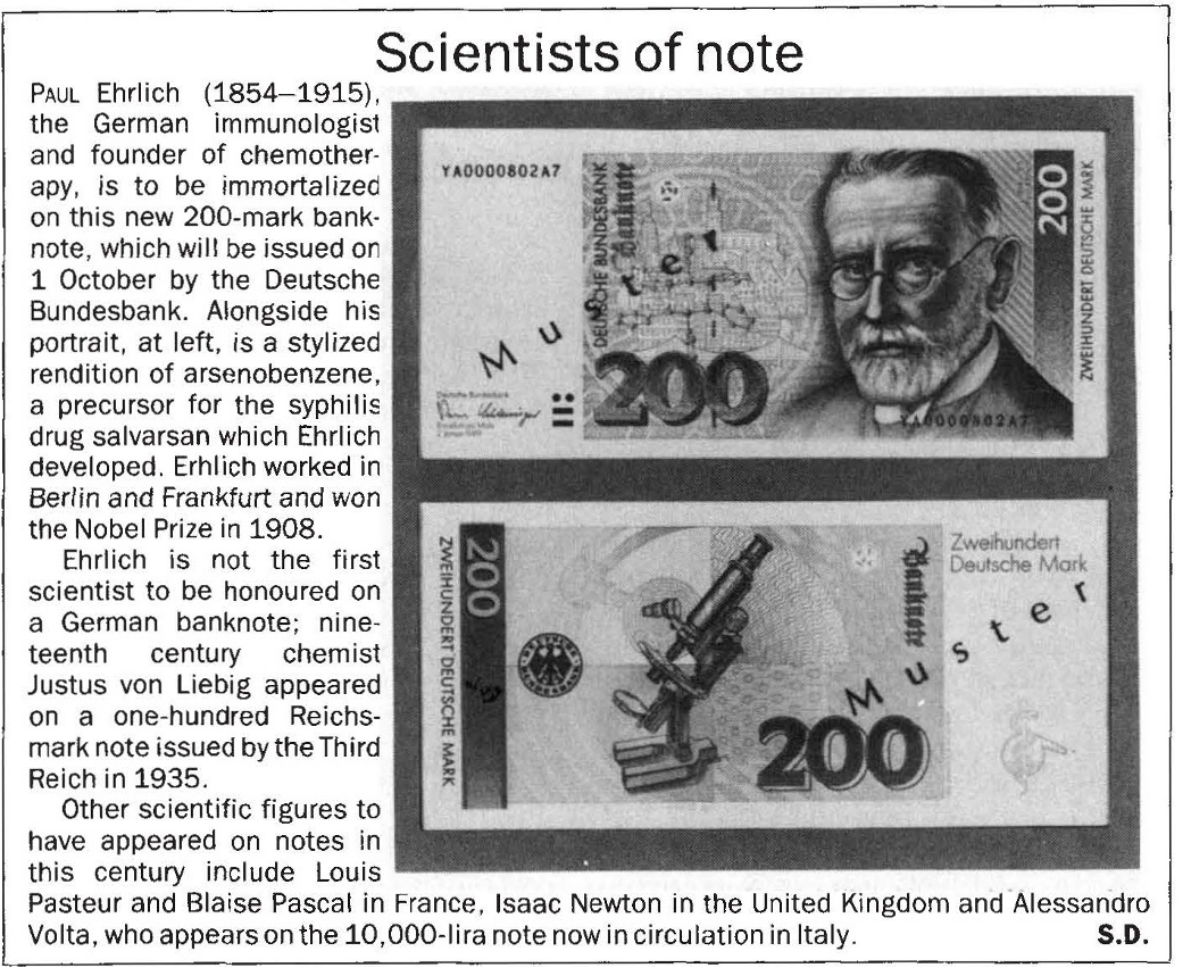

ITER PROJECT

\section{New bid for fusion}

\section{Tokyo}

JAPAN's Science and Technology Agency (STA) has decided to join the crowd by putting in a bid to base the thousand-million dollar second phase of development of the International Thermonuclear Experimental Reactor (ITER) in Japan. Nine US regional consortia, the European Communities, and the Soviet Union are also chasing the five-year engineering design phase of the project due to begin next year (see Nature 347, 114; 13 September 1990). But although Japan is not alone in the international race for ITER, it has come up with a unique domestic reason for seeking funds for the project.

The STA has asked for more than $\$ 60$ million for ITER and other activities from an unusual budgetary account, available for one year only and intended to "improve the lifestyle of the Japanese people". Most of the general accounts for the various ministries are being held steady and some, like that for the Ministry of International Trade and Industry, are even contracting. So government officials welcome the special 'lifestyle' fund set up after the United States put pressure on Japan to ease trade tensions by boosting domestic spending.

STA hopes that lifestyle funds will both support ITER and help to repair old facilities at national research institutes. STA officials argue that better national research institutes will improve the lifestyle of the Japanese people through the development of new technology, while fusion - that is, ITER - is the "ultimate energy source" which will benefit all mankind.

But Ikuo Makino, of STA's Atomic Energy Bureau, admits that once the Ministry of Finance makes a decision on the lifestyle budget requests at the end of Deceniber, any extra money received will simply be "absorbed" into STA's ordinary budget and "everyone will stop talking about improving Japanese lifestyle". D. S. US TAXES

\section{Small benefits}

\section{Washington}

Among the tax increases and levies in the new US budget agreement, which was settled in a late compromise this week, is a rare bit of good news for science. Small corporations (those with total assets of less than $\$ 50$ million) will be allowed to increase the size of their research and experimentation tax credit from 20 to 30 per cent. They will also be able to take a tax credit on scientific equipment, by writing off its total depreciation in the first year, effectively lowering the cost of the equipment and encouraging expansion. Budget negotiators estimated that the two provisions would be worth $\$ \mathbf{4 0 0}$ million to US companies. The agreement must yet be ratified by Congress before it becomes law.

C.A. 